\title{
Loneliness in old age: Psychosocial and health predictors
}

\author{
Karen Kaasa, RN \\ Vestfold College, Faculty of Health Sciences, Box 2243, 3103 Tønsberg \\ Telephone +4733031264 telefax +4733347252 e-mail Karen.Kaasa@hive.no
}

\begin{abstract}
Study objectives: The purpose of this article is to study the prevalence of loneliness in a group of elderly people over 80 years old and the sociodemographic, health-related and social predictors for experiencing loneliness.

Design: The information is obtained from a survey conducted among 232 inhabitants in this age group in the municipality of Tønsberg, its Northern District. The interview data are composed of the responses from 202 elderly people living in a house or apartment (non-institutionalized) to the question «do you generally feel lonely?».

Main results: $17 \%$ (CI 12.5-23.0) of the respondents answered yes. A significant correlation was demonstrated between a feeling of loneliness and low self-perceived health, low vision and poor hearing, low activity of daily life (ADL) function, loss of a spouse, low social network, no hobbies and possession of a safety alarm. After a multiple regression analysis of the significant variables, the remaining variables as predictors for loneliness included: number of social contacts, self-perceived health, using hearing aid and having a safety alarm.
\end{abstract}

\section{INTRODUCTION}

Old age and loneliness are linked in the stereotyped picture of old people and is one of the most widespread myths about this age group (1). It is important not to contribute to the gloomy perception of old people as lonely and unhappy (2), but nevertheless one must not underestimate the serious consequences of extreme loneliness among the elderly.

Loneliness may be defined in several different ways, often related to the cause of the loneliness. One connotation is positive, as in "solitude», deliberately chosen to be alone. Paplau and Perlman (3) studied 12 definitions of loneliness and found that all have three elements in common: First, loneliness is a result of deficiencies in a person's social relations. Second, it is a subjective feeling, not synonymous with isolation. It is possible to feel lonely together with many people or to be alone without feeling lonely. Third, the feeling is negative and unpleasant.

In this article loneliness is defined as a subjective, negative feeling related to the person's own experience of deficient social relations. Isolation is an objective assessment of a person's relations with the outside world. The determinants of loneliness are most often defined on the basis of two causal models. The first model examines the external factors which are absent in the social network as the root of the loneliness, while the second explanatory model refers to the internal factors, such as personality and psychological factors. Andersson (4) points to internal factors in an article on the importance of childhood, and concludes: «Following from the assumption that loneliness can have both developmental and situational origins, there is a need to emphasize, more than is done presently, the etiological contributions of parental influence during childhood on later experiences of loneliness» (4). Tornstam finds that both explanatory models are important in the explanation of loneliness (5).

Several studies have demonstrated a correlation between increased loneliness and a variety of predictor variables, e.g. low vision $(6,7,8)$, reduced hearing $(9,10)$, low income (3), low education (3) and loss of a spouse (2,10-12). A connection has also been demonstrated between a low activity of daily life (ADL) score and loneliness (10). However, the picture is not entirely unequivocal, since a survey from Bergen arrived at the opposite conclusion: there was increased loneliness with higher ADL independence (13). A correlation has also been established between the cognitive functional level measured by Mini Mental State Examination (MMSE) and loneliness $(10,14)$.

An extensive study in Stockholm of 1725 individuals over 80 years old concluded that loneliness is related to age, sex, marital status, social contacts, friends, health and cognitive function. The main predictors for loneliness were dissatisfaction with social contacts and habitation, followed by low self-perceived health and impaired cognitive function (10). The correlation between self-perceived health and loneliness was also shown in the Albertine project (15). The significance of a large social network is demonstrated in several studies $(2,8,9)$.

Loneliness may lead to serious health-related consequences. In the Gothenburg study Svanborg showed that loneliness results in more medical consultations (16). Loneliness is one of the three main factors leading to depression (17), and an important cause of 
suicide and suicide attempts. Hospitalization at Ullevål hospital in Oslo of patients over 70 years with selfinduced poisonings doubled in four years from 1985 to 1989. $60 \%$ were suicide attempts and loneliness and isolation were the main reason for $44 \%$ of these cases (18).

This article aims to study the extent of loneliness and possible sociodemographic, health-related and social predictors for experiencing loneliness among people over 80 years old.

\section{DATA AND METHODS}

\section{The sample}

The data in this survey are obtained from an interview survey of a random sample of $80+$ years old people in the Northern District of Tønsberg municipality. The survey was conducted in connection with the project «Quality in the municipal health services» led by Anne Sofie Brønn and the author, from May 1994 until February 1996. This article analyses the responses to the questions on loneliness from 202 non-institutionalized elderly.

The Northern District is one of three health and social services districts in Tønsberg municipality. The district includes most of the central parts of the town as well as residential districts and the farming areas outside the centre of town. The master sample for the whole survey is based on the local population register's alphabetical list of all persons over 80 living in the area as of March 1994. A random selection of this sample was made by excluding every third person on the list. The total sample consisted of 374 persons, of which 48 were dead and 3 had moved before the interviews took place. The remaining 324 received letters in the mail inviting them to participate in the survey. Of these $71 \%(n=232)$ accepted, $24 \%(n=75)$ declined and $5 \%(\mathrm{n}=16)$ could not be reached. $87 \%$ of the respondents lived in their own house, apartment or a municipality housing for pensioners, the rest lived in institutions for elderly. One of the non-institutionalized did not answer the question on loneliness.

The age distribution among the respondents was equivalent to the distribution in the total sample. The average birth year was 1909 and there was a standard deviation of 3.8 for the total sample as well as the individual interviewees. A t-test was performed which showed that there was no significant difference in average age between the total sample and the respondents. Since the age distribution among the elderly over 80 years does not follow a normal curve, a Kruskal Wallis test was performed for two of the groups. However, this test also failed to establish a significant difference between the ages of the two groups.

$75 \%$ of the interviewees were women. The age distribution is shown in table 1.

\section{Non-response}

The non-response group includes $24 \%(\mathrm{n}=75)$ who refused to participate and $5 \%(n=16)$ whom we failed to get in touch with. Concerning the latter group, we either had the letter returned or it was not possible to reach them by telephone. The reasons given by those declining to take part in the survey were mainly that they were either too ill or too well, that they didn't have time, or that they didn't feel like it. There were significantly more men than women who refused to take part. The master sample consisted of $72 \%$ women and $28 \%$ men, while the sample consisted of $76 \%$ women and $24 \%$ men.

Table 1. Age distribution among the respondents.

\begin{tabular}{lccr}
\hline & Women & Men & All \\
\hline Mean score & 85 & 85 & 85 \\
Median & 84 & 83 & 84 \\
SD & 3.5 & 3.7 & 3.6 \\
Lowest age & 80 & 80 & 80 \\
Highest age & 99 & 94 & 99 \\
\hline
\end{tabular}

\section{Method}

The interviews were conducted in the homes of the interviewees and lasted 30-140 minutes. In addition to the two project managers, three interviewers who had been trained for the task were engaged. The interviewer asked the questions and registered the answers on the questionnaire.

The data on loneliness were obtained from responses to the question: «Do you generally feel lonely?», (yes, no, I don't know). This main question was asked after several others which were used to establish contact and trust between the two parties. More detailed remarks from the interviewees were also recorded.

To measure the ADL function, the Sunnaas ADL index was utilised (19). The index is divided into 12 functions for everyday tasks. Each function is graded on a scale from $0-3$ points: 0 points for respondents requiring maximum assistance for the function in question, 1 point for human assistance, 2 points for technical aids to perform the function and 3 points when the respondent is fully capable of doing the task himself. The maximum score for total independence in everyday functions was 36 points. To indicate dementia the Mini-Mental State Examination (MMSE) method was employed. The maximum score for this test was 30, with dementia suspected by scores under 24 (20).

The respondents were also asked about the number of social contacts per week, including telephone contacts. Vision was measured on a scale from 1 to 3 , the interviewee was asked whether he or she 1) had good eyesight with or without glasses, 2) had impaired vision, 3) was blind. Hearing was registered on a scale 
from 1 to 4 , the interviewees were also asked if they used a hearing aid. The self-reported state of health was divided into five categories: 1) excellent health, 2) satisfactory health, 3) neither satisfactory nor unsatisfactory health, 4) poor health, and 5) very poor health. They were also asked if they used medication: yes or no.

\section{Processing of data}

The quantitative data were registered and processed by the computer program Epi-info. To avoid possible typing errors, all data were registered twice and the two files were run against each other. Risk ratios were measured, a 95\% confidence interval was employed as well as Fisher's exact test, two-tailed p value. A logistic regression analysis was performed with loneliness as the dependent variable and marital status, age, vision, hearing, self-perceived health, ADL function, social network, hobbies and safety alarms as independent variables.

\section{RESULTS}

Table 2 shows the composition of the survey data according to sex in relation to sociodemographic factors (marital status, age, housing and municipal relief measures), social factors (frequency of social network contacts and pursuit of hobbies), and health factors (self-perceived health, vision, hearing, ADL function, dementia and medication).

The data showed significant differences between the sexes in relation to marital status, self-perceived health, medication and municipal relief measures. 11\% of the women and $47 \%$ of the men were married. Most of the women were widows $(69 \%)$ while $47 \%$ of the men were widowers. There were important differences in terms of self-perceived health. While the men more than the women felt that their health was satisfactory or unsatisfactory, more women than men felt that their health was neither satisfactory nor unsatisfactory. There was also a distinction between men and women in terms of taking regular medication. More men $(88 \%)$ than women $(75 \%)$ took one or more forms of medication, although this is not a significant difference.

Table 3 gives a more comprehensive picture of the MMSE and the ADL function, it also shows the median and mean score as well as the SD.

To our question «Do you generally feel lonely?» $16.8 \%(n=34)$ answered yes, $80.7 \%(n=163)$ answered no and $2.5 \%(n=5)$ said they didn't know. The ones who didn't know are not included in the further analysis.

Table 4 concentrates on the 197 persons who answered yes or no to question on loneliness, distributed according to various sociodemographic, social and health-related factors.

\section{Sociodemographic factors}

There was a somewhat larger percentage of women $(17.7 \%)$ than men $(16.0 \%)$ who reported being lonely, but the difference is not significant. This survey has not demonstrated significant differences in the percentage of lonely people in the various age groups over 80 years old. With regard to marital status, there are notably more lonely people among widows/widowers than among married couples, unmarried or divorced persons. For those living at home $16 \%$ felt generally lonely, while the percentage was $22 \%$ for those living in municipal housing. This difference is not significant. It also turned out that elderly people who had installed safety alarms were notably more lonely than those without such alarms.

Table 3. MMSE and ADL scores.

\begin{tabular}{lrrr}
\hline & Women & Men & All \\
\hline Mini mental status & & & \\
Mean score & 27 & 28 & 27 \\
Median & 28 & 28 & 28 \\
SD & 3.2 & 2.8 & 3.1 \\
Lowest score & 15 & 16 & 15 \\
Highest score & 30 & 30 & 30 \\
\hline ADL function & & & \\
Mean score & 32 & 33 & 32 \\
Median & 33 & 34 & 33 \\
SD & 4.5 & 3.5 & 4.2 \\
Lowest score & 9 & 23 & 9 \\
Highest score & 36 & 36 & 36 \\
\hline
\end{tabular}

\section{Social factors}

The social network is important for the percentage of lonely people in this survey. There was notably more loneliness among the elderly who were rarely in touch with their social network, while those who had a hobby were significantly less lonely than those without a hobby.

\section{Health factors}

The results indicate an important correlation between loneliness and hearing. This is most clearly demonstrated for the elderly with hearing aids. There is also a significant connection between vision and loneliness. Respondents with poor eyesight report more loneliness. A similar correlation is demonstrated in terms of self-perceived health. There is more loneliness among respondents who report having poor health. This is also the case for interviewees with low ADL scores, while there is a significant mutual correlation between self-perceived health and ADL score. Respondents with low ADL scores perceive that their health fails them to a greater extent than others. A connection can also be found between use of medication and loneliness: respondents not using medication on a regular 
basis are less lonely than those who use medication regularly. This variable is also significantly correlated with self-perceived health.

The factors significantly associated with loneliness were then applied in a multivariate model as potential predictors of loneliness. The following factors were significantly correlated with loneliness: marital status, vision, hearing, self-perceived health, ADL score, number of network contacts and possession of a safety alarm. Non-significant predictors were then removed from the model.

Table 5 shows the results of the conclusive model: self-perceived health and very poor hearing, measured by taking into account those who had hearing aids and those who hadn't and using the same procedure for possession of safety alarm.

Table 2. The sample, according to sex, in percent.

\begin{tabular}{|c|c|c|c|c|c|}
\hline Total & $\begin{array}{c}\text { Women } \\
75 \\
\end{array}$ & $\begin{array}{c}\text { Men } \\
25\end{array}$ & $\begin{array}{l}\text { All } \\
100\end{array}$ & $\begin{array}{l}\text { (n) } \\
(197)\end{array}$ & $\begin{array}{r}\text { p-value } \\
0.000 \\
\end{array}$ \\
\hline \multicolumn{6}{|l|}{$\begin{array}{l}\text { Sociodemographic factors } \\
\text { Marital status }\end{array}$} \\
\hline Married & 11 & 41 & 18 & (36) & 1.000 \\
\hline Widow/widower & 69 & 47 & 64 & (126) & 0.008 \\
\hline Divorced & 3 & 8 & 4 & (9) & 0.177 \\
\hline Unmarried & 16 & 4 & 13 & (26) & 0.026 \\
\hline \multicolumn{6}{|l|}{ Age } \\
\hline $80-84$ & 55 & 57 & 55 & (112) & 0.912 \\
\hline $85-89$ & 36 & 31 & 35 & (71) & 0.604 \\
\hline $90-99$ & 9 & 12 & 10 & (19) & 0.628 \\
\hline \multicolumn{6}{|l|}{ Housing } \\
\hline Own house or apartment & 85 & 86 & 85 & (175) & 0.868 \\
\hline Local authority housing for pensioners & 9 & 8 & 9 & (18) & 0.891 \\
\hline Apartments for pensioners with services & 6 & 6 & 6 & (12) & \\
\hline \multicolumn{6}{|l|}{ Municipality home services } \\
\hline Has home help service & 62 & 33 & 44 & (89) & 0.000 \\
\hline Has a municipal or privat safety alarm & 25 & 8 & 21 & (43) & 0.010 \\
\hline Has home nursing care & 14 & 10 & 13 & (27) & 0.439 \\
\hline \multicolumn{6}{|l|}{ Social factors } \\
\hline \multicolumn{6}{|l|}{ Network } \\
\hline Daily contact with social network & 67 & 77 & 69 & (138) & 0.218 \\
\hline Contact with social network 2- 6 times per week & 28 & 14 & 25 & $(50)$ & 0.048 \\
\hline Contact with social network once a week or less & 5 & 10 & 6 & (12) & 0.267 \\
\hline Has a hobby & 56 & 57 & 56 & $(100)$ & 0.978 \\
\hline \multicolumn{6}{|l|}{ Health factors } \\
\hline \multicolumn{6}{|l|}{ Self-perceived health } \\
\hline Self-perceived health excellent or good & 59 & 71 & 61 & (123) & 0.106 \\
\hline Self-perceived health neither good or poor & 27 & 8 & 22 & $(45)$ & 0.005 \\
\hline Self-perceived health poor or very poor & 14 & 22 & 17 & (34) & 0.201 \\
\hline \multicolumn{6}{|l|}{ Medication } \\
\hline Takes one or more medications regularly & 75 & 88 & 79 & (159) & 0.051 \\
\hline \multicolumn{6}{|l|}{ Vision } \\
\hline Impaired vision & 10 & 8 & 10 & (20) & 0.765 \\
\hline \multicolumn{6}{|l|}{ Hearing } \\
\hline Impaired hearing & 37 & 41 & 38 & (77) & 0.680 \\
\hline Has a hearing aid & 31 & 39 & 33 & (65) & 0.260 \\
\hline \multicolumn{6}{|l|}{ ADL function } \\
\hline ADL score $>34$ & 31 & 37 & 32 & (64) & 0.539 \\
\hline ADL score 20-34 & 66 & 61 & 66 & (133) & 0.445 \\
\hline ADL score $<21$ & 31 & 2 & 2 & (5) & 0.000 \\
\hline \multicolumn{6}{|l|}{ MMSE (Mini-Mental Status) } \\
\hline MMSE score $<24$ & 13 & 10 & 12 & (16) & 0.585 \\
\hline
\end{tabular}


Table 4. Proportion of «generally lonely», percent, N=197.

\begin{tabular}{|c|c|c|c|c|}
\hline All & $\begin{array}{c}\mathbf{N} \\
197\end{array}$ & $\begin{array}{c}\text { Lonely (\%) } \\
17.3\end{array}$ & Risk ratio & $95 \%$ CI \\
\hline \multicolumn{5}{|l|}{ Sociodemographic factors } \\
\hline Men & 50 & 16.0 & 1.00 & referent \\
\hline Woman & 147 & 17.7 & 1.11 & $0.54-2.28$ \\
\hline \multicolumn{5}{|l|}{ Marital status } \\
\hline married, unmarried, divorced & 71 & 8.5 & 1.00 & referent \\
\hline widow/widower & 126 & 22.2 & 1.12 & $1.14-6.05^{*}$ \\
\hline \multicolumn{5}{|l|}{ Age } \\
\hline $80-86$ & 138 & 16.9 & 1.00 & referent \\
\hline $87-99$ & 59 & 17.4 & 1.03 & $0.52-2.01$ \\
\hline \multicolumn{5}{|l|}{ Housing } \\
\hline Own house or apartment & 170 & 16.5 & 1.00 & referent \\
\hline municipal housing & 27 & 22.2 & 1.35 & $0.62-2.95$ \\
\hline \multicolumn{5}{|l|}{ Home help } \\
\hline No & 89 & 13.5 & 1.00 & referent \\
\hline Yes & 108 & 20.8 & 1.68 & $0.81-2.93$ \\
\hline \multicolumn{5}{|l|}{ Safety alarm } \\
\hline No & 156 & 12.2 & 1.00 & referent \\
\hline Yes & 41 & 36.6 & 3.00 & $1.68-5.38 *$ \\
\hline \multicolumn{5}{|l|}{ Social factors } \\
\hline \multicolumn{5}{|l|}{ Network } \\
\hline$>1$ contact per week & 186 & 17.3 & 1.00 & referent \\
\hline$<2$ contacts per week & 11 & 45.5 & 4.51 & $1.09-18.44^{*}$ \\
\hline \multicolumn{5}{|l|}{ Hobbies } \\
\hline Yes & 98 & 12.2 & 1.00 & referent \\
\hline No & 77 & 27.3 & 2.23 & $1.17-4.24 *$ \\
\hline \multicolumn{5}{|l|}{ Health factors } \\
\hline \multicolumn{5}{|l|}{ Vision } \\
\hline Normal or impaired vison & 192 & 16.1 & 1.00 & referent \\
\hline Blind & 5 & 60.0 & 3.72 & $1.70-8.15^{*}$ \\
\hline \multicolumn{5}{|l|}{ Hearing } \\
\hline Good hearing & 122 & 13.1 & 1.00 & referent \\
\hline Poor hearing & 75 & 24.0 & 1.83 & $1.00-3.36$ \\
\hline Has not hearing aid & 132 & 12.1 & 1.00 & referent \\
\hline Has hearing aid & 65 & 27.7 & 2.28 & $1.25-4.18 *$ \\
\hline \multicolumn{5}{|l|}{ Self-perceived health } \\
\hline Excellent or good & 123 & 11.4 & 1.00 & referent \\
\hline Fair, poor or very poor & 74 & 27.0 & 2.88 & $1.26-6.63 *$ \\
\hline \multicolumn{5}{|l|}{ ADL function } \\
\hline Score $>34$ & 138 & 13.0 & 1.00 & referent \\
\hline Score $<35$ & 59 & 27.1 & 2.08 & $1.14-3.79 *$ \\
\hline \multicolumn{5}{|l|}{ Dementia } \\
\hline MMSE > 23 & 143 & 13 & 1.00 & referent \\
\hline MMSE $<24$ & 54 & 12 & 0.69 & $0.37-1.30$ \\
\hline \multicolumn{5}{|l|}{ Medication } \\
\hline No & 42 & 14.3 & 1.00 & Referent \\
\hline Yes & 154 & 18.2 & 1.27 & $0.56-2.87$ \\
\hline
\end{tabular}

* significant difference, $95 \%$ confidence interval. 
Table 5. Predictors of loneliness, logistic regression analyses.

\begin{tabular}{lccc}
\hline Predictors & Beta & OR & 95\% C.I. \\
\hline Self-perceived health & 0.45 & 1.6 & $1.04-2.40$ \\
Number of network contacts & 1.04 & 2.8 & $1.5-5.2$ \\
Hearing aid & 1.0 & 2.6 & $1.2-5.9$ \\
Safety alarm & 0.7 & 1.9 & $1.1-3.2$ \\
\hline
\end{tabular}

\section{DISCUSSION}

The interview data indicated that $17 \%$ «generally felt lonely», i.e. that they experienced loneliness to a large extent. The occurrence of loneliness among the elderly varies in different surveys. A study of 1725 people over the age of 75 showed that $35 \%$ were often or occasionally lonely, while $7 \%$ men and $12 \%$ women were often lonely, and can be compared to this survey (10). A study in Oslo from 1986 among 255 persons aged 70 and over reported that $14 \%$ (11\% men and $17 \%$ women) often felt lonely (2).

Tornstam has demonstrated considerable differences in the proportion of lonely elderly in a city in Sweden and in Finland. This could suggest that there are differences in urban and rural areas, and between various countries. An English survey demonstrated different degrees of loneliness in an urban and a rural area (12).

The survey indicates a correlation between selfperceived health and loneliness: a better state of health implies less loneliness. This finding concurs with other studies $(2,10,16)$. Both vision and hearing are significantly linked with loneliness in the survey, while hearing alone, considered in terms of having a hearing aid or not was a predictor of loneliness after a multiple regression analysis. Other studies have found a correlation with vision, and several articles have focused particularly on loneliness among the visually handicapped $(6,7,8)$. The reason why eyesight did not remain a predictor of loneliness in the final analysis is probably because it was significantly correlated with poor social network and self-perceived health which were decisive factors for the feeling of aloneness. Very poor hearing was a definite predictor of loneliness; this has also been demonstrated in other surveys $(9,10)$. Very poor hearing can cause problems in social settings. With many people present it becomes increasingly difficult to follow the conversation for a person who is hard of hearing. The hearing handicap probably results in a stronger feeling of isolation from one's surroundings, which increases the risk of feeling lonely.

The study indicated that frequency of contacts with the social network is a predictor of loneliness. Several surveys support this finding $(1,3,8,9)$.

Why is there a correlation between self-perceived health and loneliness? Do lonely people feel that their health is poor, or do people with poor health get lonely? Peplau and Perlmann's book «Loneliness» focuses on various coping mechanisms among lonely people and they suggest that «negative health effects may result from maladaptive coping activities» (3). Loneliness may lead to an unhealthy lifestyle, it may be a psychosomatic effect, or a combination of the two.

Installation of safety alarms in the old person's home is a predictor of loneliness. This has not been discussed in other studies, and this relation is difficult to interpret. One may assume that loneliness could lead to anxiety and insecurity. Surveys have shown a connection between low self-esteem and loneliness $(3,7)$. Low self-esteem and insecurity are also closely related. The correlation between loneliness and installation of a safety alarm can possibly be explained by the link between loneliness and insecurity.

The data provide a reliable picture of a crosssection of elderly over 80 years old. The occurrence of dementia measured by the MMSE $<24$ seems lower than in other surveys of people over 80 years old. It is possible that there were more elderly with dementia in the group who refused to be interviewed or that we were unable to reach. The percentage with senile dementia was $13 \%$, while in other surveys the proportion has been around $20 \%(20)$. Nevertheless, this possible skewness in the data will not affect the other results, though it may be the reason why no correlation has been demonstrated between MMSE and loneliness, as opposed to the Stockholm findings (10). Assessment of loneliness by using the question "Do you generally feel lonely, yes or no" is an inexact measure, it does not give the detailed information one gets on a scale of four. This is both a weakness and a strength: weak in the sense that most surveys often have the options: often, sometimes, rarely and never, i.e. a scale of four, and one cannot compare the results directly. However, this rough grouping clearly isolates the group in which loneliness is a real problem, while it must be regarded as less risky and normal to experience loneliness sometimes. The strength of the two-option approach is that it isolates the group with the serious degree of loneliness. This may be more difficult when the choice is between often and sometimes.

Other surveys have demonstrated the serious consequences of loneliness in the form of more medical consultations (16), suicides (18) and depressions (17). An interventional study has demonstrated that an intervention program, focusing on the CCC-design (availability of a confident, social comparison and personal control) resulted in less feeling of loneliness, less feeling of meaninglessness, more social contacts, higher self-esteem, greater ability to trust and lower blood pressure (21). Analysing the predictors of loneliness may be an instrument to reach the right target group to reduce loneliness. Creating meeting-places to establish new networks may be an important measure to help new widows and widowers as a target group. It could be useful to proceed with further studies combining qualitative and quantitative surveys to study the effect of actions to reduce loneliness among the elderly. 


\section{REFERENCES}

1. Tornstam L. Åldrandets socialpsykologi. Kristianstad: Rabén Prisma, 1994.

2. Thorsen K. Ensomhet som opplevelse og utfordring. Rapport 9-1990 Norsk gerontologisk institutt, p. 5.

3. Paplau LA, Perlman D (eds.) Loneliness. A Sourcebook of Current Theory, Research and Therapy. New York: John Wiley, 1992.

4. Andersson L. Narcissism and loneliness. Int J Aging Hum Dev 1990; 30 (2): 81-94.

5. Tornstam L, Ruth J-E, Øberg P. Ensamhetsupplevelser hos de äldra IV: Et sociohistoriskt perspektiv. Gerontologia 1990; 4 (3): 157-76.

6. Holmèn K, Andersson L, Ericsson K, Rydberg L, Winblad B. Visual impairment related to cognition and loneliness in old age. Scand J Caring Sci 1994; 8 (2): 99-105.

7. Barron CR, Foxall MJ, Dollen KV, Shull KA, Jones PA. Loneliness in low-vision older women. Ment Health Nurs 1992; 13: 387-401.

8. Barron CR, Foxall MJ, Dollen KV, Shull KA, Jones PA. Marital status, social support and loneliness in visually impaired elderly people. $J$ Adv Nurs 1994; 19: 272-80.

9. Chen H-L. Hearing in the elderly reaction of hearing loss, loneliness and self-esteem. J Gerontol Nurs 1994; June; 22-8.

10. Holmèn K, Andersson L, Ericsson K, Rydberg L, Winblad B. Loneliness among elderly people living in Stockholm: A population study. $J$ Adv Nurs 1992; 17 (1): 43-51.

11. Tornstam L. Ensamhetens ansikte. En studie av ensamhetsopplevelser hos svenskar 15-80 år, Prosjektet Äldre i samhället - Förr, nu och i fremtiden, Arbetsrapport 29, Uppsala, 1988.

12. Jones AA, Victor CR, Vetter NJ. The problem of loneliness in the elderly in the community: Characteristics of those who are lonely and the factors related to loneliness. J R Coll Gen Pract 1985; 35: 136-9.

13. Bondevik M. The life of the oldest. Studies concerning loneliness, social contacts, activities of daily living, purpose in life and religiousness. University of Bergen, 1997.

14. Holmèn K, Andersson L, Ericsson K, Rydberg L, Winblad B. ADL capacity and loneliness among elderly persons with cognitive impairment. Scand J Prim Health Care 1993; 11 (1): 56-60.

15. Lindgren AM, Svärdsudd K, Tibblin G. Factors related to perceived health among elderly people: the Albertine project. Age Ageing 1994; 23: 328-33.

16. Svanborg A. The gerontological and geriatric population study in Gothenburg, Sweden. Acta Med Scand 1977; Supplement 611: 5-112.

17. Green BH, Copeland JR, Dewey ME, Shamra V, Saunders PA, Davidson IA, Sullivan C, McWilliam C. Risk factors for depression in elderly people: a prospective study. Acta Psychiatr Scand 1992; 86 (3): 213-7.

18. Ekeberg O, Aagard I. Selvmord og selvmordsforsøk blant eldre. Tidsskr Nor Lageforen 1991; 111 (5): 562-4.

19. Varderberg K. Sunnaas ADL-index, anvendelig, gyldig og pålitelig? Prosjektrapport, Sunnaas 1993.

20. Brækhus A, Laake K, Engedal K. The Mini Mental State Examination: Identifying the most efficient variables for detecting cognitive impairment in the elderly. J Am Geriatr Soc 1992; 40 (11): 1139-45.

21. Andersson L. Aging and loneliness: An interventional study of a group of elderly women. Stockholm 1984, Department of Psychological Environmental Medicine, Karolinska Institute, Sweden. 